\title{
A novel Amperometric Gallic acid Sensor based on Polymelamine entrapped Graphene Composite
}

\author{
Tse-Wei Chen ${ }^{1}$, Selvakumar Palanisamy ${ }^{1}$, Shen-Ming Chen ${ }^{1, *}$, Vijayalakshmi Velusamy ${ }^{2}$, \\ Sayee Kannan Ramaraj ${ }^{3}$ \\ ${ }^{1}$ Department of Chemical Engineering and Biotechnology, National Taipei University of Technology, \\ Taipei 106, Taiwan (ROC) \\ ${ }^{2}$ Division of Electrical and Electronic Engineering, School of Engineering, Manchester Metropolitan \\ University, Manchester - M1 5GD, United Kingdom. \\ ${ }^{3}$ PG \& Research department of Chemistry, Thiagarajar College, Madurai-09, Tamilnadu, India. \\ *E-mail: smchen78@ms15.hinet.net
}

doi: $10.20964 / 2017.05 .03$

Received: 25 January 2017 / Accepted: 5 March 2017 / Published: 12 April 2017

The present work describes an amperometric determination of gallic acid (GA) using a glassy carbon electrode (GCE) modified with graphene (GR) and polymelamine (PM) composite. The GR/PM composite modified electrode was prepared by electropolymerization of melamine on GR modified GCE. The as-prepared GR/PM composite was characterized by scanning electron microscopy, elemental mapping and Fourier transform infrared spectroscopy. The GR/PM composite modified GCE was used as electrocatalyst for oxidation of GA, and the composite modified electrode shows an enhanced catalytic activity than electrodes modified with GR and PM. Under optimum conditions, amperometric i-t was used to determine the GA, and the amperometric response of GA was linear over the concentration ranging from 0.1 to $728.9 \mu \mathrm{M}$. The limit of detection and sensitivity of the sensor was estimated as $0.027 \mu \mathrm{M}$ and $0.697 \mu \mathrm{AMM}^{-1} \mathrm{~cm}^{-2}$, respectively. The GR/PM composite modified electrode exhibits high selectivity in the presence of range of potentially interfering polyphenol compounds, dopamine, uric acid and ascorbic acid. As a proof of concept, the practicality of the sensors was examined in green tea samples, and shows acceptable practicality for the determination of GA.

Keywords: Graphene; Poly(melamine); Gallic acid; Electro-oxidation; Amperometry

\section{$\underline{\text { FULL TEXT }}$}

(C) 2017 The Authors. Published by ESG (www.electrochemsci.org). This article is an open access article distributed under the terms and conditions of the Creative Commons Attribution license (http://creativecommons.org/licenses/by/4.0/). 